\title{
Trauer um Theda Rehbock
}

\author{
Marianne Rabe $\cdot$ Sigrid Graumann $\cdot$ Helen Kohlen
}

Angenommen: 16. Februar 2021 / Online publiziert: 24. Februar 2021

(C) Springer-Verlag GmbH Deutschland, ein Teil von Springer Nature 2021

Die Philosophin Theda Rehbock, zuletzt Professorin an der Hochschule Bochum und langjährig aktiv in der AEM, ist am 2. Januar in ihrer neuen Wahlheimat Susimetsa (Estland) gestorben.

Theda Rehbock studierte Philosophie und Germanistik in Zürich, Münster, München und Konstanz. Sie wurde 1992 an der Universität Konstanz mit der Arbeit „Goethe und die Rettung der ,Phänomene‘. Zur philosophischen Kritik des naturwissenschaftlichen Weltbildes am Beispiel der Farbenlehre“ promoviert und habilitierte sich 2003 an der Universität Dresden mit der Schrift „Personsein in Grenzsituationen. Zur Kritik der Ethik medizinischen Handelns“. Nach der Promotion war sie wissenschaftliche Mitarbeiterin an der Universität Konstanz und Postdoktorandin im Graduiertenkolleg „,Ethik in den Wissenschaften“ der Universität Tübingen. Es folgten verschiedene Stationen als wissenschaftliche Mitarbeiterin, Lehrbeauftragte, Vertretungsprofessorin und Fellow, die sie quer durch die Lande führten, darunter mehrere Jahre nach Dresden und für Forschungsaufenthalte in die USA nach Harvard und nach Estland an die Universität Tartu. Dort arbeitet ihre Freundin aus Studientagen, Prof. Dr. Margit Sutrop, mit der sie stets verbunden blieb und die sie sehr dabei unterstützte, sich in ihrer neuen Heimat wohl zu fühlen.

In der AEM wirkte sie fast 20 Jahre in der AG „Pflege und Ethik“ mit. 2009 gründete sie gemeinsam mit anderen die AG „Sprache und Ethik“, deren Koordina-

Dr. M. Rabe $(\bowtie)$

Ethikberatung, Charité Berlin, Berlin, Deutschland

E-Mail: marianne.rabe@charite.de

Prof. Dr. S. Graumann

Evangelische Hochschule Bochum, Bochum, Deutschland

Univ. Prof. Dr. H. Kohlen

Philosophisch-Theologische Hochschule Vallendar, Vallendar, Deutschland 
tion sie bis 2017 innehatte. Außerdem war sie Mitglied des Beirats der Zeitschrift „Ethik in der Medizin“.

Theda Rehbock war eine diskussionsfreudige und engagierte Kollegin und eine passionierte Lehrerin. In der Hochschule, aber auch in der Ausbildung für Ethikberater*innen und Ethiklehrende an der Charité Gesundheitsakademie hat sie anderen ihre Begeisterung für das Philosophieren nahebringen können.

Sowohl in ihrer Arbeit über die Farbenlehre als auch in ihrer Habilitationsschrift kritisiert Theda Rehbock das verbreitete naturalistische Wissenschaftsverständnis, das bis in die Ethik hineinreicht. Dabei verstand sie Kritik im philosophischen Sinn als Unterscheidung und damit als immanente Kritik, die (wie bei der Diskussion um den Personbegriff) die andere Position in ihrer Berechtigung und ihrem Beitrag zur Diskussion würdigt und im Sinne einer Metakritik gemeinsame Missverständnisse beider Gegenpositionen aufdeckt.

Theda Rehbock war eine im besten Sinn philosophische, genaue, suchende Denkerin mit der Offenheit, die philosophischen Schulen zu überschreiten. Damit stellte sie sich immer wieder quer zum Üblichen, wobei sie stets freundlich und einladend blieb. Eine Kantianerin, die für die ethische Reflexion neben Prinzipien auch den Kontextbezug für wesentlich hielt und die die oft künstliche Trennung zwischen deontologischer und teleologischer Ethik im Sinnhorizont der menschlichen Grundsituation aufgehoben sah, eine Phänomenologin und Sprachkritikerin.

Dass in ihrer Habilitationsschrift ein Kapitel über Gelassenheit enthalten ist, sagt viel über ihr Wissenschaftsverständnis aus: Sie verbindet es mit der Forderung der Selbstbescheidung (nicht nur) der Ethik angesichts der Einsicht in die Grenzen des Erkenntnisvermögens. Und sie beschreibt Gelassenheit als eine philosophische Haltung der Seelenruhe, bei der es mit Bezügen zur antiken Philosophie (Stoiker, Epikureer, Skeptiker) um Sich-Einlassen und Loslassen und somit letztlich um das gute Leben geht.

In ihrer persönlichen Geschichte ist diese Haltung sichtbar geworden: Als sie von einer unheilbaren Krankheit scheinbar begrenzt wurde, machte sie sich auf den Weg in eine neue Freiheit. Sie reiste Richtung Norden und fand ein neues Zuhause in Estland, wo sie sich in Susimetsa nahe Pärnu niederließ und im Kontakt mit ihrer Freundin Margit Sutrop, neuen estnischen Freundinnen und Freunden und alten Freundinnen und Freunden aus Deutschland und anderen Ländern das gute Leben genießen wollte. Bei ihrer Geburtstagsfeier 2020 erklang das Lied von Hannes Wader: „Heute hier, morgen dort ...“. Das sei passend, meinte sie, sie sei eine ,nomadische Existenz". Gleichzeitig war sie eine gute und treue Freundin und Weggefährtin für viele.

Der frühe Tod von Theda Rehbock hinterlässt tiefe Trauer. Uns allen, Kolleg*innen, Lernenden, Weggefährt*innen wird sie schmerzlich fehlen. Ihr reiches Wissen, ihre Erkenntnis und Inspiration wird auch zukünftig durch ihre vielfältigen Publikationen, durch ihre Student*innen, Kolleg*innen und Freund*innen Wirkung entfalten. In einem ihrer letzten Aufsätze ,Der Tod und die Toten - philosophisch betrachtet" ${ }^{* 1}$ vertieft sie ihre These, dass das Personsein mit dem Tod nicht endet,

\footnotetext{
1 In: Rehmann-Sutter (Hrsg) (2018) Was uns der Tod bedeutet. Kulturverlag Kadmos, Berlin.
} 
und spricht in Bezugnahme auf Heidegger vom „Mitsein“ der Toten, mit dem diese den Überlebenden präsent bleiben.

In diesem Sinn werden wir diese großartige Denkerin in ehrender Erinnerung behalten. 